\title{
Pengukuran dan Analisis Produktivitas Menggunakan Metode Objective Matrix (OMAX) (Studi Kasus: di PDAM Kabupaten Gorontalo)
}

\author{
Hindun Effendy*\$, Buyung R. Machmoed**, Abdul Rasyid*** \\ ${ }^{*},{ }^{* *},{ }^{* * *}$ Jurusan Teknik Industri, Fakultas Teknik, Universitas Negeri Gorontalo, Jl. Jenderal Sudirman No.6 Kota \\ Gorontalo, Indonesia 96128 \\ (hinduneffendy12@gmail.com, abdulrasyid@ung.ac.id)
}

*Penulis Koresponden; Hindun Effendy,Tel: +62822 9107 3885, hinduneffendy12@gmail.com

Dikirim: 24.02.2021 Disetujui:29.04.2021 Diterbitkan:01.05.2021

\begin{abstract}
Abstrak- Pertumbuhan penduduk di Indonesia bertambah seiring berjalannya waktu, hal ini membuat kebutuhan akan sumber daya menjadi bertambah besar, salah satunya kebutuhan air bersih. Pengukuran produktivitas dilakukan untuk mengetahui tingkat kinerja perusahaan dan dapat dijadikan sebagai pedoman untuk melakukan perbaikan yang akan datang. Perusahaan daerah air minum (PDAM) Kabupaten Gorontalo merupakan perusahaan yang bergerak dibidang jasa penyediaan air bersih melalui saluran pipa. Berdasarkan laporan posisi sambungan di PDAM Kabupaten Gorontalo diketahui sejauh ini pelayanan PDAM Kabupaten Gorontalo hanya melayani 11,6\% jumlah total kepala keluarga yang terlayani. Pengukuran produktivitas yang digunakan pada penelitian ini menggunakan metode Objective Matrix (OMAX). Tujuan penelitian ini yaitu mengukur tingkat produktivitas di PDAM Kab. Gorontalo dan melakukan evaluasi terhadap pengukuran produktivitas. Tingkat produktivitas PDAM Kabupaten Gorontalo tahun 2018 dan 2019 berdasarkan metode OMAX terjadi penurunan sebesar 76,67\% hal ini dipengaruhi oleh bobot yang ditetapkan perusahaan dengan pencapaian produktivitas perusahaan hanya sebesar $23,33 \%$. Evaluasi pengukuran produktivitas dilakukan pada input yang berkontribusi dalam penurunan produktivitas yaitu pada input energi dan tenaga.
\end{abstract}

Kata Kunci : Produktivitas, Objective Matrix (OMAX), PDAM, Efisiensi, Efektivitas

\section{Measurement and Analysis of Productivity Using the Objective Matrix (OMAX) Method \\ (Case Study: in PDAM Gorontalo District)}

\begin{abstract}
Population growth in Indonesia has increased over time, this has made the need for more resources, one of which is the need for clean water. Measurements are made to improve company performance and can be used as new ones to make future improvements. Regional drinking water company (PDAM) of Gorontalo Regency is a company engaged in providing clean water services through pipelines. Based on reports on how to connect in PDAM Gorontalo District, it is known that so far the services of PDAM Gorontalo District only serve $11.6 \%$ of the total number of families served. The productivity measurement used in this study uses the Objective Matrix (OMAX) method. The purpose of this study is to measure the level of productivity in PDAM Kab. Gorontalo and evaluate productivity and productivity. The productivity level of PDAM Gorontalo Regency in 2018 and 2019 based on the
\end{abstract}


OMAX method decreased by $76.67 \%$, this can be done by the weight set by the company with the company's productivity of only $23.33 \%$. Productivity productivity productivity inputs that contribute to productivity productivity in energy and energy inputs.

\section{Keywords: Productivity, Objective Matrix (OMAX), PDAM, Efficiency, Effectiveness}

\section{Pendahuluan}

Air bersih merupakan kebutuhan yang wajib dipenuhi setiap manusia dalam kehidupan sehari-hari. Karena itulah air bersih sangat diperlukan terutama untuk keperluan makan dan minum. Penggunaan air bersih akan bertambah seiring dengan meningkatnya jumlah penduduk, hal ini disebabkan karena keterbatasan sumber air bersih serta meningkatnya tuntutan kehidupan masyarakat yang membutuhkan air bersih.

Produktivitas merupakan hal yang sangat penting bagi perusahaan sebagai salah satu cara untuk memantau kinerja produksi. Pengukuran produktivitas dilakukan untuk mengetahui tingkat kinerja perusahaan dan dapat dijadikan sebagai pedoman untuk melakukan perbaikan yang akan datang. Peningkatan produktivitas yang dialami perusahaan disetiap periode menunjukkan bahwa perusahaan berada di posisi yang baik [1]. Terdapat tiga bentuk dasar pengukuran produktivitas. Pertama, produktivitas parsial sering disebut juga sebagai produktivitas faktor tunggal (single-factor productivity). Produktivitas parsial menunjukkan produktivitas dari faktor tertentu yang digunakan untuk menghasilkan keluaran, yang merupakan hasil pembagian dari keluaran dengan salah satu fator masukan. Kedua, produktivitas faktor total merupakan hasil pembagi dari keluaran bersih dengan beberapa masukan, seperti tenaga kerja dan modal. Keluaran bersih merupakan hasil dari keluaran total dikurangi dengan jumlah nilai barang dan jasa yang dibeli. Ketiga, produktivitas total merupakan hasil bagi keluaran dengan seluruh faktor masukan. Pengukuran produktivitas total mencerminkan pengaruh bersama seluruh masukan dalam menghasilkan keluaran [2].

Perusahaan daerah air minum (PDAM) Kabupaten Gorontalo merupakan perusahaan daerah yang berpusat di Kabupaten Limboto Kota Gorontalo. Perusahaan ini merupakan perusahaan yang bergerak dibidang jasa penyediaan air bersih melalui saluran pipa. Perusahaan ini menggunakan pedoman Permendagri Nomor 47 Tahun 1999, dimana dalam pedoman tersebut menyatakan bahwa untuk mengetahui keberhasilan Direksi dalam mengelola Perusahaan Daerah Air Minum dilakukan penilaian terhadap kinerja pada setiap akhir tahun. Dari jangkauan pelayanan PDAM menunjukkan bahwa perlu adanya peningkatan produktivitas air agar dapat meningkatkan pelayanan masyarakat yang lebih luas. Pelayanan merupakan serangkaian kegitan yang berlangsung secara rutin dan berkesinambungan dalam rangka mencapai tujuan bersama [3].
L. Greenberg mendefinisikan bahwa produktivitas sebagai perbandingan antara totalitas pengeluaran pada waktu tertentu dibagi totalitas pemasukan selama periode tersebut [4]. Produktivitas merupakan sebuah konsep yang berhubungan dengan hasil dan sumber yang telah digunakan untuk dapat menghasilkan barang tersebut [5]. Dengan diketahui nilai (index) produktivitas, maka akan diketahui pula seberapa efisien pula sumber-sumber input yang telah berhasil di hemat [6]. Input meliputi manusia, material, modal, teknologi, energi, dan informasi. Output dapat berupa produk dan jasa [7].

Peningkatan produktivitas produksi dapat dilakukan dengan dua cara, yaitu dengan pengurangan input sementara menjaga output kontan atau sebaliknya peningkatan output sementara menjaga input konstan [8]. Peningkatan produksi tidak selalu disebabkan oleh peningkatan produktivitas, karena produksi dapat meningkat walaupun produktivitas tetap atau menurun [9]. Tinggi rendahnya suatu produktivitas berkaitan dengan efisiensi dari sumber daya (input) dalam menghasilkan suatu produk atau jasa (output). Faktor umum penyebab penurunan produktivitas perusahaan yaitu; 1. Ketidakmampuan manajemen dalam mengukur, mengevaluasi, dan mengelola produktivitas perusahaan, 2. Motivasi karyawan yang rendah karena sistem pengakuan dan penghargaan yang diberikan tidak berkaitan dengan produktivitas tanggungjawab dari karyawan, 3.peningkatan biaya-biaya untuk proses produksi dan pemasaran, 4. Pemborosan (waste) penggunaan sumber daya material, tenaga kerja, energi, modal, waktu, informasi, dll, 5. Terdapat komflikkonflik dan hambatan dalam tim kerja sama yang tidak terpecahkan, sehingga menimbulkan ketidakefektifan dalam kerja sama dan partisipasi total dari karyawan, 6 . Ketiadaan sistem pendidikan dan pelatihan bagi karyawan untuk meningkatkan pengetahuan teknikteknik kualitas dan produktivitas perusahaan, 7. Kegagalan perusahaan untuk selalu menyesuaikan dengan tingkat peningkatan dan pengembangan ilmu pengetahuan dan teknologi industri, dan 8. Lain-lain yang dapat diidentifikasi dan dikembangkan sendiri sesuai dengan masalah penurunan produktivitas dan masing-masing perusahaan [5]

Terdapat beberapa metode yang dapat digunakan dalam melakukan pengukuran tingkat produktivitas. Metode objective matrix (OMAX) merupakan metode yang digunakan pada penelitian ini. Menurut Riggs (1987) OMAX merupakan suatu metode pengukuran kinerja dengan menggunakan indikator pencapaian dan suatu prosedur pembobotan untuk memperoleh indeks produktivitas total [10]. Model pengukuran OMAX 
menggabungkan kriteria-kriteria produktivitas ke dalam suatu bentuk yang terpadu dan berhubungan satu dengan yang lainnya [11]. OMAX mampu menggabungkan beberapa nilai performansi dari berbagai faktor kinerja atau kriteria menjadi satu nilai performansi tunggal, sehingga gambaran performansi secara keseluruhan dapat dilihat lebih jelas [12]. Hasil akhir dari pengukuran ini adalah nilai tunggal untuk kelompok kerja [13].

Pengukuran produktivitas penting dilakukan agar dapat mengetahui tolak ukur produktivitas yang telah dicapai oleh suatu perusahaan dan menjadi dasar perencanaan perusahaan bagi peningkatan produktivitas yang akan datang [14]. Peningkatan produktivitas perlu dimasukkan dalam program organisasi secara formal karena peningkatan produktivitas memerlukan komitmen dalam waktu yang lama [15]. Sumanth (1985) memperkenalkan suatu konsep formal yang disebut sebagai siklus produktivitas (productivity cycle) untuk dipergunakan dalam produktivitas terus menerus [16]. Siklus produktivitas ini terdiri dari empat tahap kegiatan utama, yaitu (1) Pengukuran produktivitas, (2) Evaluasi produktivitas, (3) Perencanaan produktivitas, dan (4) Peningkatan produktivitas.

Pengukuran produktivitas ini mempunyai banyak manfaat yang akan menjadi landasan dalam membuat kebijakan perbaikan produktivitas secara keseluruhan [17]. Dengan melakukan pengukuran produktivitas, maka dapat secara langsung melakukan evaluasi terhadap hasil pengukuran. Penelitian ini bertujuan untuk (1) mengukur tingkat produktivitas, (2) melakukan evaluasi terhadap pengukuran produktivitas, (3) melakukan rencana perbaikan untuk peningkatan produktivitas.

\section{Metodologi Penelitian}

Pada Gambar 1, metode pengumpulan data yang akan dilakukan pada penelitian ini terbagi dua, yaitu:

1. Data primer merupakan data yang didapatkan secara langsung di lapangan atau didapatkan dari proses pengukuran secara langsung. Data primer yang digunakan pada penelitian ini adalah wawancara dan alur proses distribusi air.

2. Data sekunder adalah data yang diperoleh dari pihak perusahaan sehingga peneliti tidak perlu mengali secara dalam sumbernya. Data sekunder yang digunakan pada penelitian ini adalah sejarah perusahaan, struktur organisasi dan manajemen perusahaan, data jumlah input dan output perusahaan, dan data mesin-mesin yang digunakan.

Berikut merupakan langkah-langkah penelitian yang akan digunakan dalam penelitian ini yaitu:

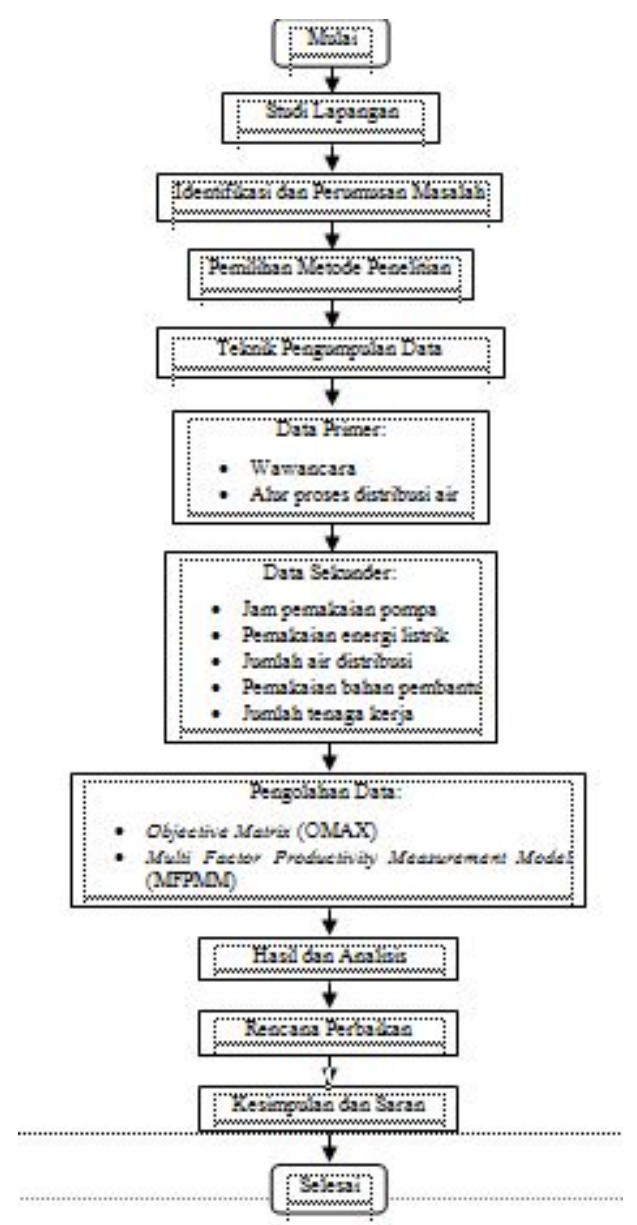

Gbr. 1. Diagram Alir Penelitian

Lokasi penelitian ini dilakukan di kantor pusat PDAM Kabupaten Gorontalo yang berada di Provinsi Gorontalo. Objek penelitian ini adalah input dan output PDAM Kabupaten Gorontalo. Adapun sampel penelitian dilakukan di Kabupaten Gorontalo. Langkahlangkah yang digunakan dalam perhitungan OMAX yaitu:

\section{Penentuan kriteria}

Hal pertama yang harus dilakukan untuk merancang model pengukuran OMAX yaitu dengan menentukan kriteria yang meliputi kriteria efisiensi, kriteria efektivitas dan kriteria inferensial.

2. Perhitungan rasio

a. Kriteria efisiensi

$$
\begin{array}{ll}
\text { Rasio I } & =\frac{\text { output }}{\text { jam kerja tahunan }} \\
\text { Rasio II } & =\frac{\text { output }}{\text { pemakaian energi listrik }} \\
\text { Rasio III } & =\frac{\text { output }}{\text { jumlah tenaga kerja }}
\end{array}
$$

b. Kriteria efektivitas

$$
\begin{array}{ll}
\text { Rasio IV } & =\frac{\text { output }}{\text { bahan pendukung }} \\
\text { Rasio V } & =\frac{\text { output }}{\text { jam penggunaan pompa }}
\end{array}
$$


c. Kriteria inferensial

$$
\text { Rasio VI }=\frac{\text { jumlah absensi }}{\text { jumlah tenaga kerja }}
$$

3. Pengukuran kinerja standar; diperoleh dari ratarata rasio masing-masing kriteria pada periode yang ditetapkan.

4. Penetapan sasaran akhir; diperoleh dari periode selanjutnya. Nilai kinerja terbaik akan diletakkan pada level 10 sedangkan nilai kinerja standar akan diletakkan pada level 3 dan yang terendah akan diletakkan pada level 0. Selanjutnya untuk semua masukkan yang lain merupakan interpolasi dari ketiga level tersebut dengan rumus:

Kenaikan level 1 dan 2 dilakukan dengan cara interpolasi:

$$
\frac{\text { level 3-level } 0}{3-0}
$$

Kenaikan level 4 sampai dengan level 9 dilakukan dengan cara interpolasi:

$$
\frac{\text { level } 10-\text { level } 3}{10-3}
$$

5. Penentuan skor aktual; ditentukan berdasarkan hasil pengukuran rasio masing-masing kriteria pada periode tertentu yang diubah kedalam skor pada matrix sasaran yang sesuai.

6. Penetapan bobot rasio; ditetapkan oleh manajer perusahaan berdasarkan sasaran peningkatan yang ingin dicapai oleh perusahaan. Bobot menunjukkan tingkat kepentingan suatu rasio menurut pihak manajemen, semakin besar bobot yang dimiliki suatu rasio, maka semakin penting pula rasio tersebut. Bobot yang digunakan untuk perhitungan nilai performansi yaitu:

$$
\text { Nilai performansi }=\text { Skor Aktual } \mathrm{x} \text { Bobot }
$$

Skor aktual menunjukkan tingkat kemungkinan tercapainya target peningkatan dengan situasi dan kondisi perusahaan sekarang. Semakin banyak skor yang baik, artinya sasaran perusahaan lebih mungkin tercapai dengan kondisi perusahaan sekarang.

7. Penentuan performance indikator; diperoleh dari jumlah nilai performansi dari semua kriteria yang dilakukan.

8. Perhitungan index produktivitas ditentukan berdasarkan rumus:

$$
\text { Index }=\frac{\mathrm{IP}_{\mathrm{i}}-\mathrm{IP}_{\mathrm{i}-\mathrm{I}}}{\mathrm{IP}_{\mathrm{i}-\mathrm{I}}} \times 100 \%
$$

Keterangan:

$\mathrm{IP}_{\mathrm{i}}=$ Indikator performansi pada suatu periode (Bulan ke-i)

$\mathrm{IP}_{\mathrm{i}-1}=$ Indikator performansi periode sebelumnya

\section{Hasil dan Pembahasan}

\section{Penentuan Kriteria}

Kriteria yang digunakan pada penelitian ini yaitu:

a. Kriteria efisiensi, yaitu menunjukkan bagaimana penggunaan sumber daya perusahaan digunakan sehemat mungkin.

b. Kriteria efektivitas, yaitu kriteria yang menunjukkan bagaimana perusahaan mencapai hasil jika dilihat dari sudut akurasi dan kualitasnya.

c. Kriteria inferensial, yaitu kriteria yang secara tidak langsung dapat mempengaruhi tetapi jika diikutsertakan dalam matriks dapat membantu memperhitungkan variabel yang mempengaruhi faktor utama.

2. Menghitung Nilai Tiap Rasio

a. Rasio I

Rasio I yaitu perbandingan antara jumlah air distribusi dengan jam kerja tahunan.

Perhitungan rasio tahun 2018:

Rasio I $=\frac{\text { Jumlah Air Distribusi }}{\text { Jumlah Jam Kerja }}$

$$
\begin{aligned}
& =\frac{540.427}{7.665} \\
& =70,506
\end{aligned}
$$

Perhitungan rasio tahun 2019:

$$
\begin{aligned}
\text { Rasio I } & =\frac{\text { Jumlah Air Distribusi }}{\text { Jumlah Jam Kerja }} \\
& =\frac{540.427}{7.665} \\
& =77,918
\end{aligned}
$$

b. Rasio II

Rasio II yaitu perbandingan antara jumlah air distribusi dengan pemakaian energi listrik.

Perhitungan rasio tahun 2018:

$$
\begin{aligned}
\text { Rasio II } & =\frac{\text { Jumlah Air Distribusi }}{\text { Jumlah Pemakaian Energi }} \\
& =\frac{540.427}{132.629} \\
& =4,075
\end{aligned}
$$

Perhitungan rasio tahun 2019:

$$
\begin{aligned}
\text { Rasio II } & =\frac{\text { Jumlah Air Distribusi }}{\text { Jumlah Pemakaian Energi }} \\
& =\frac{540.427}{145,813} \\
& =4,096
\end{aligned}
$$

c. Rasio III

Rasio III yaitu perbandingan antara jumlah air distribusi dengan jumlah tenaga kerja.

Perhitungan rasio tahun 2018:

$$
\begin{aligned}
\text { Rasio III } & =\frac{\text { Jumlah Air Distribusi }}{\text { Jumlah Tenaga Kerja }} \\
& =\frac{540.427}{5} \\
& =108.085,400
\end{aligned}
$$

Perhitungan rasio tahun 2019:

$$
\begin{aligned}
\text { Rasio III } & =\frac{\text { Jumlah Air Distribusi }}{\text { Jumlah Tenaga Kerja }} \\
& =\frac{540.427}{6} \\
& =99.540,167
\end{aligned}
$$


d. Rasio IV

Rasio IV yaitu perbandingan antara jumlah air distribusi dengan bahan pendukung.

Perhitungan rasio tahun 2018:

$$
\begin{aligned}
\text { Rasio IV } & =\frac{\text { Jumlah Air Distribusi }}{\text { Jumlah Bahan Pendukung }} \\
& =\frac{540.427}{27.527} \\
& =19,633
\end{aligned}
$$

Perhitungan rasio tahun 2019:

$$
\begin{aligned}
\text { Rasio IV } & =\frac{\text { Jumlah Air Distribusi }}{\text { Jumlah Bahan Pendukung }} \\
& =\frac{597.241}{28.900} \\
& =20,666
\end{aligned}
$$

e. Rasio V

Rasio V yaitu perbandingan antara jumlah air distribusi dengan jam mesin tersedia.

Perhitungan rasio tahun 2018:

$$
\begin{aligned}
\text { Rasio V } & =\frac{\text { Jumlah Air Distribusi }}{\text { Jumlah Jam Penggunaan Pompa }} \\
& =\frac{540.427}{22.721} \\
& =23,785
\end{aligned}
$$

Perhitungan rasio tahun 2019:

$$
\begin{aligned}
\text { Rasio V } & =\frac{\text { Jumlah Air Distribusi }}{\text { Jumlah Jam Penggunaan Pompa }} \\
& =\frac{597.241}{24.405} \\
& =24,472
\end{aligned}
$$

f. Rasio VI

Rasio VI yaitu perbandingan antara jumlah absensi dengan jumlah tenaga kerja.

Perhitungan rasio tahun 2018:

$$
\begin{aligned}
\text { Rasio VI } & =\frac{\text { Jumlah Absensi }}{\text { Jumlah Tenaga Kerja }} \\
& =\frac{57}{5} \\
& =11,40
\end{aligned}
$$

Perhitungan rasio tahun 2019:

$$
\begin{aligned}
\text { Rasio VI } & =\frac{\text { Jumlah Absensi }}{\text { Jumlah Tenaga Kerja }} \\
& =\frac{59}{6} \\
& =9,83
\end{aligned}
$$

\section{Pengukuran Kinerja Standar}

Pengukuran kinerja standar merupakan hasil hitungan pada masing-masing rasio. Hasil rekapitulasi perhitungan rasio dapat dilihat pada Tabel 1.

Tabel 1. Hasil Perhitungan Tiap Rasio

\begin{tabular}{lccr}
\hline \multicolumn{1}{c}{ Rasio } & 2018 & 2019 & $\mu$ \\
\hline Rasio I & 70.50581 & 77.91794 & 74.21187 \\
Rasio II & 4.074727 & 4.095938 & 4.085333 \\
Rasio III & 108085.4 & 99540.17 & 103812.8 \\
Rasio IV & 19.63262 & 20.66578 & 20.1492 \\
Rasio V & 23.78535 & 24.47208 & 24.12871 \\
Rasio VI & 11.40 & 9.83 & 10.61667 \\
\hline
\end{tabular}

Pada Tabel 1 diatas, sebelum menetapkan sasaran akhir, terlebih dahulu ditentukan standar deviasi. Standar devasi bertujuan untuk mendapatkan nilai degree of accuracy yang kemudian akan menentukan nilai confident level. Setelah itu, akan didapatkan nilai Batas Kontrol Atas dan Batas Kontrol Bawah.

Nilai degree of accuracy didapatkan dengan membagi nilai $\mu$ dan standar deviasi. Setelah itu, penentuan nilai confident level dengan cara mengurangi angka 1 dengan nilai degree of accuracy. Batas control atas didapatkan dengan menjumlahkan nilai $\mu$ dengan angka 1 yang kemudian dikali dengan nilai standar deviasi. Setelah itu menentukan batas control bawah dengan mengurangi nilai $\mu$ dengan angka 1 yang kemudian dikali dengan standar deviasi pada masing-masing rasio.

\section{Penetapan Sasaran Akhir}

Penetapan sasaran akhir terdiri dari nilai kinerja terbaik, nilai kinerja terendah, dan nilai kinerja standar. Nilai kinerja terbaik diletakkan pada level 10 sedangkan nilai kinerja standar akan diletakkan pada level 3 dan nilai kinerja terendah diletakkan pada level 0 . Selanjutnya untuk semua masukkan yang lain merupakan hasil interpolasi dari ketiga level tersebut dengan rumus yang terdapat pada halaman.

Berikut merupakan contoh cara melakukan interpolasi untuk Rasio I adalah sebagai berikut:

- Kenaikan level 1 dan 2 dilakukan dengan cara interpolasi, yaitu:

$$
\begin{aligned}
\text { Kenaikan level } 1 \text { dan } 2 & =\frac{\text { Level } 3-\text { Level } 0}{3-0} \\
& =\frac{70,50-68,97}{3} \\
& =0,512
\end{aligned}
$$

- Kenaikan level 4 sampai dengan level 9 dengan cara interpolasi, yaitu:

$$
\begin{aligned}
\text { Kenaikan level } 4 \text { dan } 9 & =\frac{\text { Level } 10-\text { Level } 3}{10-3} \\
& =\frac{79,45-68,97}{7} \\
& =1,27
\end{aligned}
$$

Perhitungan untuk setiap rasio dapat dilakukan dengan cara yang sama.

\section{Penentuan Skor Aktual}

Menentukan skor aktual masing-masing rasio yaitu dengan melihat nilai pada skor performasi yang mendekati nilai aktual. Nilai aktual diperoleh dari perhitungan masing-masing rasio setiap periode.

\section{Penetapan Bobot Rasio}

Penetapan bobot rasio berguna untuk mengetahui nilai kepentingan dari masing-masing rasio yang diukur. Semakin penting suatu rasio bagi perusahaan, maka semakin tinggi bobot yang diberikan perusahaan terhadap rasio tersebut. 
Bobot rasio ini ditetapkan oleh pihak manajemen perusahaan. Adapun skala yang digunakan pada penelitian ini yaitu menggunakan skala likert. Berikut merupakan keterangan skala likert:

Nilai $1=$ Mutlak Tidak Penting

Nilai 2 = Kurang Penting

Nilai 3 = Penting

Nilai 4 = Sangat Penting

Nilai 5 = Mutlak Penting

\section{Penentuan Performance Indikator}

Penentuan performance Indikator dilakukan setiap bulan selama periode pengukuran, yaitu dimulai dari bulan Januari 2018 sampai dengan bulan Desember 2019. Setelah pembobotan selesai dilakukan selanjutnya yaitu pembentukan matriks yang telah diterapkan.

Langkah-langkah yang digunakan dalam melakukan perhitungan performance indikator adalah sebagai berikut:

- Menentukan skor aktual masing-masing rasio
- Menghitung nilai skor performansi, yaitu dengan mengalikan skor aktual masing-masing rasio dengan bobot rasio tersebut Menghitung indikator indikator pencapaian, yaitu dengan menjumlahkan seluruh nilai performasi.

\section{Perhitungan Indeks Produktivitas}

Setelah diperoleh nilai indikator pencapaian pada tiap bulan selama periode pengukuran, selanjutnya nilai-nilai indikator pencapaian tersebut digunakan untuk menghitung indeks produktivitas perusahaan setiap bulan selama periode pengukuran.

Indeks produktivitas merupakan perbandingan nilai indikator produktivitas suatu periode dengan indikator periode sebelumnya. Hasil perhitungan indeks produktivitas setiap periode menggambarkan penurunan dan peningkatan produktivitas yang telah dicapai oleh perusahaan. Indeks produktivitas dapat dilihat pada Tabel 2.

Tabel 2. Matriks Sasaran PDAM Kabupaten Gorontalo Untuk Tahun 2018 Dan 2019

\begin{tabular}{|c|c|c|c|c|c|c|}
\hline \multicolumn{7}{|c|}{ Metode OMAX Bobot Perusahaan } \\
\hline $\mathrm{R} 1$ & $\mathrm{R} 2$ & $\mathrm{R} 3$ & $\mathrm{R} 4$ & $\mathrm{R} 5$ & $\mathrm{R} 6$ & Rasio \\
\hline 77,92 & 4,10 & $99.540,17$ & 20,67 & 24,47 & 9,83 & Performance \\
\hline 79,45 & 4,10 & $109.855,18$ & 20,88 & 24,61 & 12,83 & 10 \\
\hline 78,17 & 4,10 & $109.602,35$ & 20,70 & 24,50 & 12,63 & 9 \\
\hline 76,90 & 4,09 & $109.349,53$ & 20,52 & 24,38 & 12,42 & 8 \\
\hline 75,62 & 4,09 & $109.096,70$ & 20,35 & 24,26 & 12,22 & 7 \\
\hline 74,34 & 4,09 & $108.843,88$ & 20,17 & 24,14 & 12,01 & 6 \\
\hline 73,06 & 4,08 & $108.591,05$ & 19,99 & 24,02 & 11,81 & 5 \\
\hline 71,78 & 4,08 & $108.338,23$ & 19,81 & 23,90 & 11,60 & 4 \\
\hline 70,51 & 4,07 & $108.085,40$ & 19,63 & 23,79 & 11,40 & 3 \\
\hline 69,99 & 4,07 & $104.647,06$ & 19,56 & 23,74 & 10,40 & 1 \\
\hline 69,48 & 4,07 & $101.208,73$ & 19,49 & 23,69 & 9,40 & 0 \\
\hline 68,97 & 4,07 & $97.770,39$ & 19,42 & 23,64 & 8,40 & Skor \\
\hline 9 & 10 & 0 & 9 & 9 & 2 & Bobot \\
\hline 2 & 1 & 2 & 1 & 3 & 3 & Nilai \\
\hline 18.000 & 10.000 & 0.000 & 9.000 & 27.000 & 6.000 & Indeks Performansi \\
\hline \multicolumn{7}{|c|}{70} \\
\hline \multicolumn{7}{|c|}{$-76.67 \%$} \\
\hline \multicolumn{7}{|c|}{ Turun } \\
\hline
\end{tabular}

Pada Tabel 2 dapat dilihat bahwa indeks produktivititas yang didapatkan adalah $-76.67 \%$. Ini artinya, pencapaian produktivitas perusahaan hanyalah senilai $23,33 \%$

Berdasarkan data historis dari tahun 2018 dan 2019 lebih banyak terjadi kenaikan di tahun 2019. Nilai input di tahun 2019 mengalami penurunan. Sedangkan outputnya mengalami kenaikan. Hal ini sesuai dengan syarat naiknya produktivitas. Namun hasil yang didapatkan tidak menunjukkan kenaikan. Bobot yang ditentukan oleh perusahaan juga menjadi penentu pada naik turunnya nilai indeks produktivitas. Berikut merupakan hasil produktivitas berdasarkan bobot yang ditetapkan oleh peneliti dapat dilihat pada Tabel 3.

Berdasarkan Tabel 3, bobot yang ditetapkan oleh peneliti adalah berdasarkan nilai kepentingan dari kriteria satu terhadap kriteria lainnya. Hasil menunjukkan kenaikan produktivitas sebesar $33.25 \%$. Hal ini berarti, perusahaan telah berhasil mencapai tingkat produktivitas $100 \%$ yang kemudian pada tahun 
2019 mengalami kenaikan sebanyak 33,25\%.

Nilai produktivitas masih bisa dinaikan dengan cara melakukan simulasi terhadap input yang kemudian dapat menaikkan nilai output. Kenaikan produktivitas dapat diupayakan dengan memaksimalkan kualitas dari jumlah tenaga kerja yang ada, kemudian mengurangi pemborosan pada penggunaan bahan baku dan energi di setiap bulannya.

Tabel 3. Hasil OMAX Berdasarkan Pembobotan Peneliti

\begin{tabular}{|c|c|c|c|c|c|c|}
\hline \multicolumn{7}{|c|}{ Metode OMAX } \\
\hline $\mathrm{R} 1$ & $\mathrm{R} 2$ & R3 & R4 & R5 & R6 & Rasio \\
\hline 77.92 & 4.10 & 99540.17 & 20.67 & 24.47 & 9.83 & Performance \\
\hline 79.45 & 4.10 & 109855.18 & 20.88 & 24.61 & 12.83 & 10 \\
\hline 78.17 & 4.097 & 109602.35 & 20.70 & 24.50 & 12.63 & 9 \\
\hline 76.90 & 4.093 & 109349.53 & 20.52 & 24.38 & 12.42 & 8 \\
\hline 75.62 & 4.089 & 109096.70 & 20.35 & 24.26 & 12.22 & 7 \\
\hline 74.34 & 4.086 & 108843.88 & 20.17 & 24.14 & 12.01 & 6 \\
\hline 73.06 & 4.082 & 108591.05 & 19.99 & 24.02 & 11.81 & 5 \\
\hline 71.78 & 4.078 & 108338.23 & 19.81 & 23.90 & 11.60 & 4 \\
\hline 70.51 & 4.07 & 108085.40 & 19.63 & 23.79 & 11.40 & 3 \\
\hline 69.99 & 4.073 & 104647.06 & 19.56 & 23.74 & 10.40 & 2 \\
\hline 69.48 & 4.072 & 101208.73 & 19.49 & 23.69 & 9.40 & 1 \\
\hline 68.97 & 4.07 & 97770.39 & 19.42 & 23.64 & 8.40 & 0 \\
\hline 9 & 10 & 0 & 9 & 9 & 2 & Skor \\
\hline 30.80 & 23.79 & 5.21 & 11.70 & 3.68 & 23.12 & Bobot \\
\hline 277.200 & 237.900 & 0.000 & 105.300 & 33.120 & 46.240 & Nilai \\
\hline \multicolumn{6}{|c|}{700} & Indeks Performansi \\
\hline \multicolumn{6}{|c|}{$133.25 \%$} & Indeks Produktivitas \\
\hline \multicolumn{6}{|c|}{ Naik 33.25\% } & Keterangan \\
\hline
\end{tabular}

\section{Kesimpulan dan Saran}

Tingkat produktivitas PDAM Kabupaten Gorontalo tahun 2018 dan 2019 berdasarkan metode OMAX terjadi penurunan sebesar $76,67 \%$ hal ini dipengaruhi oleh bobot yang ditetapkan perusahaan dengan pencapaian produktivitas perusahaan hanya sebesar 23,33\%. Evaluasi pengukuran produktivitas dilakukan pada input yang berkontribusi dalam penurunan produktivitas yaitu pada input energi dan tenaga. Rencana perbaikan dilakukan dengan memaksimalkan kuantitas dari jumlah tenaga kerja yang ada, serta mengurangi pemakaian pompa pada waktu beban puncak dan menambah kapasitas pompa sehingga pemborosan yang terjadi dapat diminimalisir.

Dalam upaya peningkatan kinerja tahun berikutnya pihak perusahaan dapat memperhatikan bobot kepentingan tiap rasio sehingga tingkat produktivitas akan naik. Pihak perusahaan disarankan untuk dapat menggunakan sensor tekanan agar pemborosan akibat kebocoran/kehilangan air dapat diatasi dengan cepat.

\section{Daftar Pustaka}

[1] E. Z. Afianti, I. K. Satriawan, dan I. W. G. S. Yoga, "Analisis Produktivitas Produksi PT . Bapak Bakery Badung Bali," J. Rekayasa dan Manaj. Agroindustri, vol. 8, no. 1, hal. 127138, 2020.

[2] D. Pramestari, "Penentuan Kriteria Perbaikan Produktivitas Pada Suatu Departemen Kerja Dengan Menggunakan Metode Objective Matrix (OMAX)," IKRAITH-TEKNOLOGI, vol. 2, no. 2, hal. 9-19, 2018.

[3] E. Wolok, "Strategi Membangun Kepuasan Pelanggan Melalui Mutu Pelayanan Pada CV Cokro 2000," J. Apl. Manaj., vol. 8, no. 598605, 2010.

[4] R. Walangitan, "Produktivitas Tenaga Kerja Dengan Menggunakan Metode Work Sampling Pada Pekerjaan Kolom dan Balok Mega Trade Center Manado," J. TEKNO-SIPIL, vol. 10, no. 57, hal. 14-20, 2012.

[5] P. P. Wardoyo dan Y. Hadi, "Peningkatan Produktivitas UMKM Menggunakan Metode 
Objective Matrix," J. Ilm. Tek. Ind., vol. 4, no. 1, hal. 1-8, 2016.

[6] A. Z. Al Faritsy dan Suseno, "Peningkatan Produktivitas Perusahaan Dengan Menggunakan Metode Six Sigma, Lean dan Kaizen," J. Tek. Ind., vol. 10, no. 2, hal. 103$116,2015$.

[7] S. Junus dan I. H. Lahay, "Perencanaan Kebutuhan Hasil Perikanan Tangkap dan Komoditi Laut Lainnya Melalui Pendekatan Metode Material Requipment Planning (MRP) Dalam Upaya Peningkatan Pendapatan Nelayan Gorontalo," Semin. Nas. Teknol. dan Rekayasa, hal. 97-104, 2016.

[8] J. Supono dan T. Widodo, "Penerapan Metode Line Balancing Untuk Peningkatan Produktivitas Pada Jalur Lintasan CPLG Extension di PT. ABC," J. Tek., vol. 4, no. 1, hal. 10-23, 2015.

[9] Pribadiyono, "Aplikasi Sistem Pengukuran Produktivitas Kaitannya Dengan Pengupahan," J. Tek. Ind., vol. 8, no. 2, hal. 114-121, 2006.

[10] A. Afifi, I. . M. Tuningrat, dan I. K. Satriawan, "Analisis Produktivitas Produksi di Perusahaan Kecap Manalagi Denpasar," J. Rekaya dan Manaj. Argoindustri, vol. 3, no. 3, hal. 133142, 2015.

[11] F. Agustina dan N. A. Riana, "Analisis Produktivitas dengan Metode Objective Matrix (OMAX) di PT. X,” J. Tek. dan Manaj. Ind., vol. 6, no. 2, hal. 150-158, 2011.

[12] M. I. Fajrianto, T. G. Amran, dan N. Azmi, "Rancang Bangun Model Lean Productivity Dengan Pendekatan Objective Matrix-Value Stream Mapping-Ecrs (Studi Kasus: PT. X), " J. Tek. Ind., vol. 5, no. 3, 2017, doi: 10.25105/jti.v5i3.1521.
[13] D. Avianda, Y. Yuniati, dan Yuniar, "Strategi Peningkatan Produktivitas di Lantai Produksi Menggunakan Metode Objective Matrix (OMAX )," J. Online Inst. Teknol. Nas., vol. 01, no. 04, hal. 202-213, 2014.

[14] R. Sinaga, "Analisis Produktivitas Dengan Menggunakan Metode American Productivity Center dan Objective Matrix (Studi Kasus: Di PT. XYZ Toili)," Universitas Negeri Gorontalo, 2019.

[15] E. Maulana dan S. Perdana, "Analisis Produktivitas Departemen Servis pada PT TI Dengan Metode Objective Matrix (OMAX)," $J$. IKRA-ITH Teknol., vol. 4, hal. 21-30, 2020.

[16] D. Suhardini, A. K. Pakpahan, dan A. T. Astuti, "Pengukuran Produktivitas Lini Produksi Produk Panel Box PT. Dwimukti Graha Elektrindo Dengan Menggunakan Metode Objective Matrix (OMAX) dan Perbaikan Produktivitas," J. Tek. Ind., no. 1411-6340, hal. 101-113, 2016.

[17] G. R. Firdaus, "Analisis Produktivitas Produksi Edamame Fresh Menggunakan Multi Faktor Productivity Measurement Model (MFPMM) dan Failure Modes and Effect Analysis di PT. Gading Mas Indonesia Teguh (GMIT)," Universitas Brawijaya, 2017. 